\title{
Use and Rotation of Opioids in Chronic Non-oncologic Pain
}

\author{
Durval Campos Kraychete, TSA ${ }^{1}$, Rioko Kimiko Sakata, TSA ${ }^{2}$
}

Summary: Kraychete DC, Sakata RK - Use and Rotation of Opioids in Chronic Non-oncologic Pain.

Background and objectives: Prolonged use of opioids is a possibility for chronic pain treatment. Opioids are effective for virtually all chronic noncancer pain syndromes, but may cause dependence. The aim of this paper is to review the use and rotation of opioids in chronic non-oncologic pain.

Content: The use of potent opioids is controversial and not recommended as first-line drugs due to the possibility of dependence. The following topics are described: tolerance, addiction, risk factors for addiction, rotation or replacement, general administration rules, conversion tables, and tips for prescribing opioids.

Conclusions: Opioids are drugs with proven efficacy for chronic non-oncologic pain, but its prescription should meet certain criteria in order to reduce the incidence of adverse effects and addiction.

Keywords: Chronic Pain; Analgesics, Opioid / adverse effects.

@2012 Elsevier Editora Ltda. All rights reserved.

\section{INTRODUCTION}

Opioids are effective for virtually all chronic non-cancer pain syndromes. Many patients require potent opioids for pain relief 1 .

The use of potent opioids can be justified for chronic nononcologic pain when other techniques are ineffective, but requires careful monitoring of patients. The use of potent opioids is controversial and not recommended as first-line drugs due to the possibility of dependence. Psychological dependence (addiction) is not frequent when opioids are wisely administered. Several investigators have shown that the prevalence of abuse occurs in $18-41 \%$ of patients receiving opioids for chronic pain treatment ${ }^{2}$.

For treatment of chronic pain, the long-term use of opioids is a possibility along with the knowledge of concepts related to tolerance (reduced drug effect, irrespective of dose increase), chemical dependency, opioid rotation, and monitoring of adverse effects common to the use of these agents.

With careful management by a professional and responsible use by the patient, the relationship between benefit and side effects is good for many patients. The use of opioids for

Received from Departamento de Anestesiologia, Universidade Federal da Bahia and Departamento de Anestesiologia, Dor e Terapia Intensiva, Universidade Federal de São Paulo.

1. Associate Professor of Anesthesiology, Universidade Federal da Bahia; Coordinator of the Pain Clinic, Hospital das Clínicas and Hospital Aristides Maltez.

2. MD; Coordinator of the Department of Pain, Universidade Federal de São Paulo.

Submitted on November 29, 2010.

Approved on September 5, 2011.

Correspondence to:

Rioko Kimiko Sakata, MD

Rua Três de Maio 61, apto 51,

Vila Clementino

04044020 - São Paulo, SP, Brazil

E-mail: riokoks.dcir@epm.br non-oncologic pain should follow the same principles used for cancer pain: preference for oral therapy, fixed intervals, following the analgesic ladder, individualized use ${ }^{3}$, dose titration $^{3}$, and prevention and treatment of side effects ${ }^{4}$.

Opioids are used to relieve pain from various syndromes, such as lumbago ${ }^{5-7}$, osteoarthritis ${ }^{7,8}$, neuropathy ${ }^{7}$, rheumatoid arthritis ${ }^{6}$.

\section{Tolerance}

Development of opioid tolerance is related to various molecular and cellular reasons (reduction or excessive increase in the number of opioid receptors, mechanisms for G-proteincoupled, internalization of the opioid-receptor complex) and can occur with any opioids, and at different times even in the same patient.

Thus, tolerance may develop from the first day of treatment during long-term use and after opioid switch. In the latter, however, tolerance happens in an incomplete manner. This could be related to a specific action of a subtype receptor, for example, NMDA for methadone, $\mu_{2}$ for fentanyl, and $\mu_{1}$ for morphine and hydromorphone. There is also the possibility of a specific receptor for morphine-6-glucuronide (M6-G), an active metabolite of morphine. Likewise, there may be difference in efficacy. Morphine that has low efficiency needs to occupy a larger number of receptors than fentanyl, which has high efficiency, for an analgesic response. Thus, a drug that occupies a greater number of receptors, such as intravenous infusion of opioids, more easily induces tolerance. It is important to recognize that there are genetic differences in response to pain and in the variability of opioid receptors, particularly between male and female ${ }^{9}$. 


\section{Addiction}

Several studies have shown that careful evaluation of patients with chronic use of opioids is important.

Addicted patients have some warning signs that should be noted:

- Use of opioids in a compulsive manner to solve their conflicts and not to relieve pain;

- Increase dose on their own;

- Do not accept the prescribed medication or ask for more;

- Ask prescription from several doctors;

- Do not accept changes in treatment;

- Change in behavior;

- Lose control over prescription, using more and more opioid:

- Use the opioid despite the side effects caused by overdose, being unable to pay attention to responsibilities and obligations.

\section{Risk factors for addiction}

Risk factors for addiction are:

- Genetics (family history of alcoholism and drug use);

- Personal history of addition, psychiatric disorders, and sexual abuse.

Patients at risk for dependence need more control through more frequent doctor visits, prescription that is more restrictive, smaller amount of analgesic given with each prescription, urine or blood tests, information given by family. According to one study, about $7 \%$ of the professionals order urine drug tests before prescribing opioids and $15 \%$ order it in patients using opioids ${ }^{10}$.

\section{Choice of opioid}

Long-acting controlled-release opioid formulations should be chosen. Oral morphine is also a good option for selected patients with non-oncologic pain. In a meta-analysis, opioids were used for nociceptive pain, neuropathic pain, fibromyalgia, and mixed pain in $80 \%, 12 \%, 7 \%$, and $1 \%$ of patients, respectively. The weak opioids used were tramadol, propoxyphene, and codeine and the potent ones were morphine and oxycodone ${ }^{3}$. Some authors use transdermal fentanyl $4,5,8$. Treatment should be based on equivalent doses of opioids. Morphine should be initiated with immediate release formulation and then switched to slow release. The advantage of slow-release morphine is the reduction of side effects, as serum concentrations are small and do not exceed the threshold for toxicity.

\section{Opioid rotation or switch}

Rotation of opioids involves the practice of changing one opioid to another in an attempt to better control the pain or reduce the adverse effects (cognitive impairment, hallucinations, delirium, myoclonus, nausea, vomiting, constipation, and orthostatic hypotension). The incidence of this practice varies from $15 \%$ to $40 \%{ }^{11,12}$.

Doctors often need to switch from one opioid to another during treatment due to numerous reasons. The reasons for switch or rotation are inadequate pain relief with increasing dose, intolerable side effects, loss of route of administration, and cost 13,14 .

Rotation is used to obtain better analgesic effect that has been compromised by tolerance. The act of converting an opioid remains difficult for many professionals. Part of this difficulty is due to weak evidence in literature to support the equianalgesic ratio. There are no conversion algorithms or guides. The final decision to prescribed opioids should involve clinical assessment to minimize risk of prescribing inappropriate dose to patient's current need ${ }^{15}$.

Opioid does not always fails to promote adequate effect due to tolerance. Sometimes, non-cancer pain may not be relieved with increased dose of opioids because patients experienced side effects with a lower dose than required for effective analgesia. In other patients, pain stimulus is very intense and partially relieved by opioids. Opioid rotation can significantly improve the relationship of analgesia and side effects. The reason for rotating can influence dosage of opioid. Conversion should not merely be calculated mathematically, but as part of the evaluation of pain intensity of side effects, comorbidities, and concomitant analgesics.

For best results, the dose should be individualized, particularly when rotation involves large doses of opioids, due to the wide variation of the conversion dose.

In systematic review, most authors use morphine as a firstline opioid and, often, methadone as the second choice ${ }^{16}$. All authors concluded that opioid switching is a useful maneuver to improve pain control and reduce side effects. However, the evidence supporting this practice is based on uncontrolled studies. There is a need for study the cases in which patients act as their own controls to establish the true effectiveness of this practice, determine which should be the first-line opioid, and establish a standard conversion of one opioid to another ${ }^{16}$.

Evaluation of the patient is the most important step in the equianalgesic conversion process ${ }^{13}$. The conversion must take into account the patient's individual characteristics, such as age, renal function, side effects, and pain syndrome ${ }^{13}$. After conversion, titration, and adjustment for each patient, it is necessary to ensure that transition is smooth and promotes the analgesia required for adequate pain relief.

The reasons for opioid rotation are little studied, but complex, and involve pharmacokinetic and pharmacodynamic factors. Reduced analgesic efficacy due to tolerance, genetic differences in response to drugs, and changes in bioavailability may occur. Similarly, adverse effects may be difficult to 
control due to interaction with other drugs, changes in protein binding (greater fraction of free agent), accumulation of active metabolites, and chronic renal failure. Other reasons for opioid switching would be related to the maximum dose allowed (360 mg for codeine), agent availability for that route of administration, and cost 11,12 .

Opioid rotation is performed in the following conditions ${ }^{11,12 \text { : }}$

1. Pain intensity is greater than or equal to 4 (numerical scale from 0 to 10), despite the increasing dose of morphine;

2. Patient presents with myoclonus, hallucination or delusion;

3. Nausea and vomiting;

4. Oversedation;

5. Local toxicity;

6. Need for alternative routes;

7. High cost;

8. Non-acceptance by the patient.

\section{General rules for administration of opioids $11,12,17,18,19$}

To reduce the risks in prescribing potent opioids, certain principles should be followed.

- Use in patients who failed with other alternatives.

- Opioid treatment is complementary to other analgesic and techniques.

- Investigation to ensure the existence of actual source of persistent pain.

- Individualized treatment.

- Rule out the possibility that pain is caused by psychiatric illness.

- History of drug abuse and chaotic family environment are relative contraindications.

- Patient must cooperate with the doctor in order to achieve pain relief and functional restoration.

- Prescription should be written at a Clinical Service, preferably by a single professional.

- Fixed-dose and pill counting.

- Start with low dose.

- Informed consent and agreement may be used.

- If there is not at least partial relief, treatment should be questioned.

- Frequent assessment of pain relief, side effects, functional status, and behavior.

- Continue if the dose is stable, with analgesia, and no abuse.

- Discontinue if there is no analgesia, functional improvement, abuse, side effects, and dose increase.

\section{Opioid conversion tables}

Note that the most common errors in opioid switching are related to incorrect dose conversion to new route of administration, problems with titration, and inadequate use of other drugs and techniques.
Equianalgesic dose is defined as the dose frequency of two agents to produce the same effect. There are several tables, however, empirical or based on study with cancer patients using low doses of opioids. There are conversion tables for professionals with some knowledge of the doses when switching an opioid to another. After conversion, the dose should be modified as needed according to clinical effect, as tables are only guides to facilitate the management.

Table I - Example of Opioid Conversion

\begin{tabular}{|c|c|c|}
\hline Opioids & Parenteral & Oral \\
\hline Morphine to oxycodone & $1: 0.7$ & $2: 1$ \\
\hline Oxycodone to morphine & $0.7: 1$ & $1: 1.5$ \\
\hline Morphine to hydromorphone & $5: 1$ & $5: 1$ \\
\hline Hydromorphone to morphine & $1: 3.5$ & $1: 3.5$ \\
\hline \multirow[t]{6}{*}{ Morphine to methadone } & $1: 1^{*}$ & < 100 mg: $3: 1$ \\
\hline & & $101-300 \mathrm{mg}: 5: 1$ \\
\hline & & $301-600$ mg: $10: 1$ \\
\hline & & $601-800$ mg: $12: 1$ \\
\hline & & $801-1,000$ mg: $15: 1$ \\
\hline & & > 1,000 mg: $20: 1$ \\
\hline Hydromorphone to morphine & $1: 1^{*}$ & $\begin{array}{l}1: 1 \text { for low doses, } \\
\text { then use the same } \\
\text { criterion of morphine }\end{array}$ \\
\hline Hydromorphone to fentanyl & $20: 1$ & $\begin{array}{l}\text { Convert to IV and } \\
\text { then to }\end{array}$ \\
\hline Morphine to fentanyl & $100: 1$ & $\begin{array}{l}\text { Oral to transdermal } \\
100: 1\end{array}$ \\
\hline
\end{tabular}

* initial, reducing according to response.

Table II - Example of Conversion from Intravenous to Transdermal Fentanyl

\begin{tabular}{ll}
\hline Intravenous & Transdermal \\
\hline $8-25 \mathrm{mcg} \cdot \mathrm{h}^{-1}$ & $25 \mathrm{mcg} \cdot \mathrm{h}^{-1}$ \\
$26-42 \mathrm{mcg} \cdot \mathrm{h}^{-1}$ & $50 \mathrm{mcg} \cdot \mathrm{h}^{-1}$ \\
$43-58 \mathrm{mcg} \cdot \mathrm{h}^{-1}$ & $75 \mathrm{mcg} \cdot \mathrm{h}^{-1}$ \\
$59-75 \mathrm{mcg} \cdot \mathrm{h}^{-1}$ & $100 \mathrm{mcg} \cdot \mathrm{h}^{-1}$ \\
Any increase over $\mathbf{1 7} \mathrm{mcg} \cdot \mathrm{h}^{-1}$ & Add $25 \mathrm{mcg} \cdot \mathrm{h}^{-1}$ \\
\hline
\end{tabular}

Tips $17,18,19,20,21,22,23$

1. Use the equianalgesic table.

2. Determine the point in which effect is significant.

3. If switching to another opioid other than methadone or fentanyl, reduce the dose by $25 \%$ to $50 \%$.

4. If switching to methadone, reduce the dose by $75 \%$ to $90 \%$.

5. If switching to transdermal fentanyl, do not change the dose.

6. Dose adjustment to more or less according to clinical signs/symptoms, especially in the elderly, organ failure, or severe pain.

7. Monitoring of adverse effects 
8. The association of drugs acting on the same type of receptor is not recommended.

9. According to some authors, switching morphine to fentanyl is better than to oxycodone or methadone. Adverse effects, such as delirium, sedation, dry mouth, nausea, vomiting, and myoclonus, are less intense.

10. Morphine is the standard opioid. Equivalent oral doses:

Morphine $10 \mathrm{mg}=$ codeine $60 \mathrm{mg}$

Morphine $30 \mathrm{mg}=$ oxycodone $20 \mathrm{mg}$

Morphine $60 \mathrm{mg}=$ transdermal fentanyl $25 \mathrm{mcg}$

Morphine $30 \mathrm{mg}$ = hydromorphone $4 \mathrm{mg}$

Morphine $=6 \mathrm{mg}$ buprenorphine $0.2 \mathrm{mg}$

11. Morphine PO to IV: reduce the dose by three times.

12. Morphine PO to subcutaneous: reduce the dose by twice.

13. Hydromorphone IV to subcutaneous: increase $20 \%$.

14. Morphine $10 \mathrm{mg}=$ oral transmucosal fentanyl $800 \mathrm{mcg}$.

15. There is great interindividual variability in methadone pharmacokinetics, as well as potential to cause delayed toxicity. There is report of cardiotoxicity with sudden death. Thus, the equianalgesic ratio ranges from $16: 1$ to $2.5: 1$, depending on the time of previous exposure to opioid, total dose of opioids, reason for rotation (pain or adverse effects), in addition to interaction with other drugs. Conversion ratio of $5: 1$ is used for morphine doses lower than $300 \mathrm{mg}$, and if the reason for rotation is pain, this ratio may decrease to $3: 1$. The conversion rate of 10:1 should then be used for morphine doses greater than $300 \mathrm{mg}$ in patients with anxiety, depression, delirium, or requiring rapid increase in dosage and those with creatinine greater than or equal to $1.5 \mathrm{mg} \cdot \mathrm{dL}^{-1}$. If the reason for rotation is pain, this rate may decrease 5:1. Methadone should be titrated up or down every 48 or 72 hours by about $30-50 \%$, assessing the clinical criteria, degree of patient's satisfaction, and need for dose of escape. While morphine requirement is inversely proportional to age, this relationship is independent for methadone. Some authors also did not correlate the dose equivalence in the conversion of morphine to methadone to sex, characteristics of cancer and its treatment, biochemical or hematological parameters. On the other hand, there are few studies of methadone transition to another opioid. Some authors suggest that methadone $10 \mathrm{mg}$ is equivalent to morphine 20,33 or $77.5 \mathrm{mg}$, hydromorphone $4.5,3$ or $50 \mathrm{mg}$, fentanyl 200,400 or $2,000 \mathrm{mcg}$. This wide variation in literature, in addition to the pharmacokinetic and pharmacodynamic properties of methadone, suggests that methadone should be gradually discontinued until complete introduction of the new agent.

16. Differentiate tolerance (increasing the dose to achieve the same effect) from physical dependence (withdrawal syndrome) and addiction (compulsive need of the drug to maintain a feeling of well-being).

17. Treat constipation and vomiting side effects. Behavioral disorders and drowsiness limit the use of the drug. Note these effects for a week before switching to another technique.

18. Do not use meperidine, it leads to the formation of toxic metabolites (normeperidine) that accumulate in the body and cause central nervous irritability.

19. Pay attention to opioid-induced toxicity, a clinical condition characterized by changes in sensitivity (allodynia and hyperalgesia), higher doses of opioids, myoclonus, seizures, and cardiac arrest. 


\section{REFERENCES}

1. Quigley C - Opioid switching to improve pain relief and drug tolerability. Cochrane Database Syst Rev 2004; (3):CD004847.

2. Trescot AM, Boswell MV, Atluri SL, et al. - Opioid Guidelines in the Management of Chronic Non-Cancer Pain. Pain Phys 2006; 9:1-40.

3. Furlan AD, Sandoval JA, Mailis-Gagnon A, et al. - Opioids for chronic pain: a meta-analysis of effectiveness and side effects. CMAJ 2006; 174(11):1589.

4. Vallerand $\mathrm{AH}$ - The use of long-acting opioids in chronic pain management. Nurs Clin North Am 2003; 38(3):435-445.

5. Allan L, Richarz U, Simpson K, et al. - Transdermal fentanyl versus release oral morphine in strong-opioid naive patients with chronic low back pain. Spine 2005; 30(22):2484-2490. 
6. Solomon DH, Avom J, Wang PS, et al. - Presciption opioid use among older adults with arthritis or low back pain. Arthritis Rheum 2006; 55(1):35-41.

7. Colzzi F, Mattia C - Oxycodone. Pharmacological profile and clinical data inchronic pain managment. Min Anesthesiol 2005; 71(7-8):451460.

8. Langford R, McKenna F, Ratcliffe S, et al. - Transdermal fentanyl for improvement of pain and functioning in osteoarthritis: A randomized, placebo-controlled trial. Arthitis Rheum 2006; 54(6):1829-1837.

9. Smith MT - Opioid-induced hyperalgesia, opioid rotation and opioid combinations. Acute Pain 2008; 10:199- 200.

10. Tellioglu $T$ - The use of urine drug testing to monitor patients receiving chronic opioid therapy for persistent pain conditions. Med Health R I. 2008 Sep;91(9):279-280, 282.

11. Souter KJ, Fitzgibbon D - Equianalgesic dose guidelines for long-term opioid use: Theoretical and practical considerations. Sem Anesth Perioper Med Pain, 2004; 23(4):271-280.

12. Anderson $\mathrm{R}$, Saiers $\mathrm{JH}$, Abram $\mathrm{S}$, et al - Accuracy in equianalgesic dosing: Conversion dilemmas. J Pain Symptom Manage 2001; 21(5):397-406.

13. Brant JM - Opioid equianalgesic conversion: the right dose. Clin $\mathrm{J}$ Oncol Nurs 2001; 5(4):163-165

14. Caims R - The use of oxicodone in cancer-related pain: a literature review. Int J Palliat Nurs 2001; 7(11):522-527.

15. Gammaitoni AR, Fine $P$, alvarez N, et al. - Clinical application of opioid equianalgesic data. Clin J Pain 2003; 19(5):286-297.

16. Ginsberg B, Sinatra RS, Adler LJ, et al. - Conversion to oral controlledrelease oxycodone from intravenous opioid analgesic in postoperative setting. Pain Med 2003; 4(1):31-38.

17. Boubekeur N, Delorme J, Roussel P - Échelle d'équivalences des antalgiques (EDEA): mise au point d'un outil pour la conversion équianalgésique. Douleurs 2006; 7(4):201-206.

18. Benítez-Rosario MA, Salinas-Martín A, Aguirre-Jaime A, et al. - Morphine-methadone opioid rotation in cancer patients: Analysis of Dose Ratio Predicting Factors. J Pain Symptom Manage 2009; 37(6):061068.

19. Coluzzi F, Pappagallo M - Opioid therapy for chronic non-cancer pain: Practice guidelines for initiation and maintenance of therapy. Min Anestesiol 2005; 71:425-433.
20. Grilo RM, Bertin P, Scotto di Fazano C, et al. - Opioid rotation in the treatment of joint pain. A review of 67 cases. Joint Bone Spine 2002; 69:491-494.

21. Moryl N, Santiago-Palma J, Kornick C, et al. - Pitfalls of opioid rotation: substituting another opioid for methadone in patients with cancer pain. Pain 2002; 96:325-328.

22. Morita T, Takigawa C, Onishi $\mathrm{H}$ et al. - Opioid Rotation from Morphine to fentanyl in Delirious Cancer Patients: An Open-Label Trial. J Pain Symptom Manage2005; 30(1):96-103.

23. McNicol E, Horowicz-Mehler N, Fisk RA, et al. - Management of opioid side effects in cancer-related and chronic noncancer pain: A systematic review. J Pain 2003; 4:231-256. 